\title{
Perception of the COVID-19 Epidemic and Acceptance of Vaccination Among Healthcare Workers Prior to Vaccine Licensure - Beijing Municipality, China, May-July 2020
}

\author{
Luodan Suo'; Rui Ma'; Zhongzhan Wang'; Tian Tang²; Haihong Wang 3 ; Fang Liu';

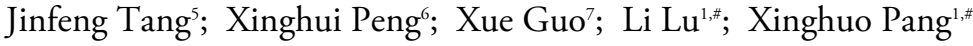

\section{Summary \\ What is already known about this topic? \\ The coronavirus disease 2019 (COVID-19) vaccine development has been progressing, but acceptance of the new vaccines by healthcare workers (HCWs) was not well known prior to approval of COVID-19 vaccines in China. \\ What is added by this report? \\ This study found that before vaccine approval, Beijing HCWs expressed moderate willingness to get vaccinated. Factors positively influencing willingness included free vaccination and belief that the vaccine had been fully evaluated. A negatively influencing factor was presence of an underlying disease. Trust in vaccines, in general, was positively associated with willingness to get new vaccines. \\ What are the implications for public health practice? \\ COVID-19 vaccines should be provided at no cost to HCWs. Effective measures should be taken to enhance the acceptance of COVID-19 vaccination among HCWs in China.}

The coronavirus disease 2019 (COVID-19) vaccines are expected to be widely used, but awareness and acceptance of the new COVID-19 vaccines by healthcare workers (HCWs) was not well known prior to approval by China's vaccine regulatory authority. The research conducted a cross-sectional survey in Beijing to assess HCWs' perceptions of the COVID-19 epidemic and attitudes towards vaccination before COVID-19 vaccines were approved. Multivariate analyses were used to evaluate factors associated with willingness to get vaccinated. A total of 8,040 HCWs were recruited; $67.1 \%$ reported they would get vaccinated, while the rest were unsure or indicated they would not get vaccinated. Factors associated with willingness to get vaccinated included the epidemic situation and its prognosis, perception of disease severity, and perceived risk of getting infected. Multivariate analyses found two factors strongly associated with willingness, "wanting the vaccine to be free of charge" (OR: 5.78, 95\% CI: 5.05-6.60, $P<0.001)$ and "belief that the vaccine was fully evaluated prior to licensure" (OR: 4.45, 95\% CI: 3.81-5.20, $P<0.001)$. One factor, "presence of an underlying disease" was found to be negatively associated with willingness (OR: 0.74, 95\% CI: $0.61-0.90, P<0.001)$. The results supported a free vaccination policy and use of effective measures to remove barriers and convey accurate information about COVID-19 vaccines to enhance acceptance of the vaccines among HCWs in China.

The COVID-19 pandemic, caused by the COVID-19 virus also known as SARS-CoV-2, has resulted in global public health and economic crises (1). The general consensus is that successful vaccines should be developed to reduce morbidity and mortality caused by the disease (2). Many countries have been promoting vaccine research and achieving landmark results over the past months (3). Several vaccines completed Phase III clinical trials and have been put into extensive use.

Based on previous experience, it is highly likely that $\mathrm{HCWs}$ will be recommended as a priority population for vaccination. Experience has shown that even if vaccines are successfully developed, the acceptance may not be ideal (4). In China, where non-pharmacological interventions (5) have been strictly implemented and the epidemic effectively controlled, awareness and acceptance by HCWs of the new vaccines are not well known. This study conducted a cross-sectional survey in Beijing to provide a reference for formulating rational vaccination strategies.

The setting was 6 (Chaoyang, Fengtai, Changping, Daxing, Miyun, and Huairou) of the 16 districts in Beijing. Overall, ten hospitals, including two Level III general hospitals, two Level II general hospitals, and six Level I hospitals or communities health centers were selected in each district by a systematic sampling 
method. These hospitals were responsible for diagnosis and treatment of COVID-19 cases, community population screening, and nucleic acid sampling during the epidemic. All doctors, nurses, and technicians in high-risk departments/units were included. In nonhigh-risk departments, at least five doctors and five nurses were included, unless there were fewer than five doctors or nurses, in which case all were included.

The investigation began in early May 2020 and ended in mid-July 2020 (prior to emergency use authorization of any COVID-19 vaccine in China). An anonymous questionnaire was administered through a WeChat App. Questions included demographic characteristics, perceptions of risk towards the COVID-19 epidemic and severity of the disease, attitudes towards COVID-19 vaccination, and past vaccination history. Five-point Likert scales were used, and responses were classified into three categories positive, negative, and uncertain. The research implemented quality control measures to ensure achieving target numbers of respondents.

Univariate analysis included frequency and ratio calculations and Pearson's chi-squared test for differences. Multivariate stepwise logistic regression was used to evaluate factors associated with intention to accept vaccination. All variables significant at the $P<0.1$ level in univariate logistic regression were included in multivariable stepwise logistic regression analyses. Odds ratios and $95 \%$ confidence intervals were calculated. Alpha was set at 0.05. Statistical analyses were performed using the Statistical Package for Social Sciences (SPSS/PASW, version 19.0, SPSS Inc, Chicago, IL, USA.).

A total of $8,040 \mathrm{HCWs}$ participated in the survey; 3,844 (47.8\%) were nurses; 2,836 (35.3\%) were doctors; and 1,360 (16.9\%) were technicians. Most $(90.4 \%)$ respondents were less than 50 years old and most were female $(80.4 \%)$; $70.3 \%$ had participated in prevention and control of the COVID-19 epidemic; $34.4 \%$ came from departments directly involved in diagnosis and treatment of COVID-19 patients; $35.1 \%$ reported having received other vaccines in the past three years; and $10.9 \%$ reported presence of an underlying disease.

Most respondents considered that consequences of COVID-19 infection were "serious", and $80.1 \%$ perceived they might become infected by the virus; $57.5 \%$ indicated that they were at greater risk of COVID-19 virus infection than others. Nearly half were unsure whether the outbreak would come back and thought the global epidemic would last a long time; $67.6 \%$ agreed that the epidemic could be prevented by vaccination, and a slightly lower proportion believed in the safety and effectiveness of the vaccine; $73.0 \%$ reported their life had been seriously disturbed by the epidemic in the past months; $43.6 \%$ estimated life and work would continue to be disturbed in the next six months (Table 1).

Respondents believed more in professional staff advice $(94.1 \%)$ compared with statements from media (80.4\%); $80.0 \%$ of HCWs were convinced the vaccine had been fully evaluated in clinical trials, and $77.4 \%$ wanted the vaccine to be free of charge; $67.1 \%$ of the respondents reported they would get vaccinated, while $7.9 \%$ said they would not, and $25.0 \%$ were unsure. The percentage of respondents who would advise family members to get vaccinated $(68.2 \%)$ was similar to their own willingness to be vaccinated; however, fewer $(61.9 \%)$ were willing to vaccinate their children. Among willing respondents, vaccination campaigns organized by their hospital (75.3\%) were more acceptable than vaccination offered by community clinics $(24.7 \%)$. Doctors, nurses, and technicians answered questions similarly (Table 2).

Results of univariate logistic regression of intention to accept COVID-19 vaccination and related variables are shown in Table 3. In multiple logistic regression models, positive factors significantly associated with intention to get vaccinated included "received other vaccines in the past three years," "received seasonal influenza vaccine," agreed with "suffering from COVID-19 virus infection is serious," "China's epidemic will come back," "the global epidemic will last for a long time," "COVID-19 can be prevented by vaccination", "the vaccine is safe," and "the vaccine is effective." Overall, two factors showed stronger positive associations - "wanting the vaccine to be free of charge" (OR: 5.78, 95\% CI: 5.05-6.60, P<0.001) and "believing the vaccines approved for license have been fully evaluated" (OR: 4.45, 95\% CI: 3.81-5.20, $P<0.001)$; one factor was negatively associated "presence of an underlying disease" (OR: 0.74, 95\% CI: $0.61-0.90, P<0.001)$. Gender, age, occupational cohort, ward type, hospital level, academic degree, salary, participation in prevention and control of the epidemic, and perception of infection risk were not associated with intention to be vaccinated.

\section{DISCUSSION}

This study, which was conducted before completion of Phase III vaccine clinical trials, found that HCWs in Beijing were moderately willing to accept COVID-19 vaccination and that their willingness was strongly associated with perception of whether the vaccine is free and safe. Our results supported implementation of 
TABLE 1. Healthcare worker perceptions of the COVID-19 epidemic by occupation category, Beijing Municipality, China.

\begin{tabular}{|c|c|c|c|c|c|}
\hline Question & Total, $\mathrm{n}=8,040(\%)$ & Doctors, $\mathrm{n}=2,836(\%)$ & Nurses, $n=3,844(\%)$ & Technicians, $n=1,360(\%)$ & $P$ value* \\
\hline \multicolumn{6}{|c|}{ Q1 Is suffering from SARS-CoV-2 infection serious? } \\
\hline Not serious & $33(0.4)$ & $14(0.5)$ & $10(0.3)$ & $9(0.7)$ & $<0.001$ \\
\hline Little serious & $307(3.8)$ & $176(6.2)$ & $95(2.5)$ & $36(2.6)$ & \\
\hline Serious & $7,700(95.8)$ & $2,646(93.3)$ & $3,739(97.3)$ & $1,315(96.7)$ & \\
\hline \multicolumn{6}{|c|}{ Q2 Are you likely to be infected by SARS-CoV-2? } \\
\hline Unlikely & $2,135(26.6)$ & $612(21.6)$ & $1,000(26.0)$ & $523(38.5)$ & $<0.001$ \\
\hline Likely & $4,382(54.5)$ & $1,646(58.0)$ & $2,094(54.5)$ & $642(47.2)$ & \\
\hline Very likely & $1,523(18.9)$ & $578(20.4)$ & $750(19.5)$ & 195(14.3) & \\
\hline \multicolumn{6}{|c|}{ Q3 Are you at greater risk of SARS-CoV-2 infection than other people? } \\
\hline Agree & $4,627(57.5)$ & $1,815(64.0)$ & $2,277(59.2)$ & $535(39.3)$ & $<0.001$ \\
\hline Disagree & $1,353(16.8)$ & $480(16.9)$ & $542(14.1)$ & $331(24.3)$ & \\
\hline Unsure & $2,060(25.6)$ & $541(19.1)$ & $1,025(26.7)$ & $494(36.3)$ & \\
\hline
\end{tabular}

Q4 If you were infected by SARS-CoV-2, do you think you will suffer from more serious symptoms than others?

$\begin{array}{lrrrr}\text { Agree } & 1,247(15.5) & 420(14.8) & 643(16.7) & 184(13.5) \\ \text { Disagree } & 2,034(25.3) & 759(26.8) & 912(23.7) & 363(26.7) \\ \text { Unsure } & 59.2(59.2) & 1,657(58.4) & 2,289(59.5) & 813(59.8)\end{array}$

Q5 Do you think China's COVID-19 epidemic will come back?

$\begin{array}{lrrrr}\text { Agree } & 1,850(23.0) & 788(27.8) & 850(22.1) & 212(15.6) \\ \text { Disagree } & 2,144(26.7) & 726(25.6) & 951(24.7) & 467(34.3) \\ \text { Unsure } & 4,046(50.3) & 1,322(46.6) & 2,043(53.1) & 681(50.1)\end{array}$

Q6 Do you think the global COVID-19 epidemic will last for a long time?

$\begin{array}{lrrrr}\text { Agree } & 3,996(49.7) & 1,679(59.2) & 1,738(45.2) & 579(42.6) \\ \text { Disagree } & 1,141(14.2) & 378(13.3) & 539(14.0) & 224(16.5) \\ \text { Unsure } & 2,903(36.1) & 779(27.5) & 1,567(40.8) & 557(41.0)\end{array}$

Q7 Do you think COVID-19 can be prevented by vaccination?

$\begin{array}{lcccc}\text { Agree } & 5,439(67.6) & 1,976(69.7) & 2,556(66.5) & 907(66.7) \\ \text { Disagree } & 450(5.6) & 181(6.4) & 208(5.4) & 61(4.5) \\ \text { Unsure } & 2,151(26.8) & 679(23.9) & 1,080(28.1) & 392(28.8)\end{array}$

Q8 Do you think COVID-19 vaccines are safe?

$\begin{array}{lcccc}\text { Agree } & 4,929(61.3) & 1,727(60.9) & 2,363(61.5) & 839(61.7) \\ \text { Disagree } & 101(1.3) & 34(1.2) & 47(1.2) & 20(1.5) \\ \text { Unsure } & 3,010(37.4) & 1,075(37.9) & 1,434(37.3) & 501(36.8) \\ \text { Q9 Do you think COVID-19 vaccines are effective? } & & & 0.902 \\ \text { Agree } & 5,024(62.5) & 1,761(62.1) & 2,401(62.5) & 862(63.4) \\ \text { Disagree } & 48(0.6) & 24(0.8) & 20(0.5) & 4(0.3) \\ \text { Unsure } & 2,968(36.9) & 1,051(37.1) & 1,423(37.0) & 494(36.3)\end{array}$

Q10 How disrupted has your work and life been in the past three months due to the epidemic?

$\begin{array}{lcccc}\text { Not serious } & 253(3.1) & 62(2.2) & 137(3.6) & 54(4.0) \\ \text { Little serious } & 1,921(23.9) & 588(20.7) & 1,003(26.1) & 330(24.3) \\ \text { Serious } & 5,866(73.0) & 2,186(77.1) & 2,704(70.3) & 976(71.8)\end{array}$

Q11 In the next period of time (six months), how much do you expect your work and life to be disrupted by the epidemic?

\begin{tabular}{lcccc} 
Not serious & $792(9.9)$ & $269(9.5)$ & $377(9.8)$ & $146(10.7)$ \\
Little serious & $3,746(46.6)$ & $1,308(46.1)$ & $1,802(46.9)$ & $636(46.8)$ \\
Serious & $3,502(43.6)$ & $1,259(44.4)$ & $1,665(43.3)$ & $578(42.5)$ \\
\hline
\end{tabular}

${ }^{*} X^{2}$ test. 
TABLE 2. Healthcare worker attitudes toward COVID-19 vaccination by occupation category, Beijing Municipality, China.

\begin{tabular}{|c|c|c|c|c|c|}
\hline Questions & $\begin{array}{c}\text { Total, } \\
\mathrm{n}=\mathbf{8 , 0 4 0}(\%) \\
\end{array}$ & $\begin{array}{c}\text { Doctors, } \\
\mathrm{n}=2,836(\%)\end{array}$ & $\begin{array}{c}\text { Nurses, } \\
\mathrm{n}=\mathbf{3 , 8 4 4}(\%)\end{array}$ & $\begin{array}{c}\text { Technicians, } \\
\mathrm{n}=1,360(\%)\end{array}$ & $P$ value* \\
\hline \multicolumn{6}{|c|}{ Q1 Do you trust the official statements from the media? } \\
\hline Believe & $6,462(80.4)$ & $2,385(84.1)$ & $2,983(77.6)$ & $1,094(80.4)$ & $<0.001$ \\
\hline Disbelieve & $319(4.0)$ & $99(3.5)$ & $171(4.4)$ & $49(3.6)$ & \\
\hline Unsure & $1,259(15.7)$ & $352(12.4)$ & $690(18.0)$ & $217(16.0)$ & \\
\hline \multicolumn{6}{|c|}{ Q2 Do you trust professional staff advice? } \\
\hline Believe & $7,563(94.1)$ & $2,663(93.9)$ & $3,634(94.5)$ & $1,266(93.1)$ & 0.266 \\
\hline Disbelieve & $31(0.4)$ & $13(0.5)$ & $14(0.4)$ & $4(0.3)$ & \\
\hline Unsure & $446(5.5)$ & $160(5.6)$ & $196(5.1)$ & $90(6.6)$ & \\
\hline
\end{tabular}

Q3 If the COVID-19 vaccine is approved for licensure, do you want it to be free of charge?

$\begin{array}{lcccc}\text { Yes } & 6,221(77.4) & 2,125(74.9) & 3,043(79.2) & 1,053(77.4) \\ \text { No } & 293(3.6) & 127(4.5) & 115(3.0) & 51(3.8) \\ \text { Either is OK } & 1,526(19.0) & 584(20.6) & 686(17.8) & 256(18.8)\end{array}$

Q4 Do you believe that COVID-19 vaccine approved for licensure will have been fully evaluated in clinical trials?

$\begin{array}{lcccc}\text { Believe } & 6,431(80.0) & 2,220(78.3) & 3,118(81.1) & 1,093(80.4) \\ \text { Disbelieve } & 144(1.8) & 75(2.6) & 49(1.3) & 20(1.5) \\ \text { Unsure } & 1,465(18.2) & 541(19.1) & 677(17.6) & 247(18.2)\end{array}$

Q5 Will you get vaccinated with a COVID-19 vaccine?

$\begin{array}{lcccc}\text { Yes } & 5,395(67.1) & 1,849(65.2) & 2,636(68.6) & 910(66.9) \\ \text { No } & 632(7.9) & 269(9.5) & 251(6.5) & 112(8.2) \\ \text { Unsure } & 2,013(25.0) & 718(25.3) & 957(24.9) & 338(24.9)\end{array}$

Q6 Where would you like to get the COVID-19 vaccine? ${ }^{\dagger}$

$\begin{array}{lcccc}\begin{array}{l}\text { Community vaccination clinic } \\ \text { Vaccination campaign }\end{array} & 1,331(24.7) & 478(25.9) & 570(21.6) & 283(31.1) \\ \begin{array}{l}\text { organized by hospital } \\ \text { Q7 Will you advise your family members to get the COVID-19 vaccine? }\end{array} & 4,064(75.3) & 1,371(74.1) & 2,066(78.4) & 627(68.9) \\ \text { Yes } & 5,486(68.2) & 1,857(65.5) & 2,682(69.8) & 947(69.6) \\ \text { No } & 514(6.4) & 213(7.5) & 214(5.6) & 87(6.4) \\ \text { Unsure } & 2,040(25.4) & 766(27.0) & 948(24.7) & 326(24.0)\end{array}$

Q8 Will you take your children to get the COVID-19 vaccine? ${ }^{\S}$

$\begin{array}{lcccc}\text { Yes } & 2,643(61.9) & 995(59.5) & 1,221(62.3) & 427(67.0) \\ \text { No } & 359(8.4) & 154(9.2) & 159(8.1) & 46(7.2) \\ \text { Unsure } & 1,267(29.7) & 523(31.3) & 580(29.6) & 164(25.7)\end{array}$

Q9 Who do find most trustworthy for offering COVID-19 vaccine information (multiple choice)?

\begin{tabular}{|c|c|c|c|c|c|}
\hline Official media & $6,862(85.3)$ & $2,379(83.9)$ & $3,346(87.0)$ & $1,137(83.6)$ & $<0.001$ \\
\hline Medical specialist & $7,134(88.7)$ & $2,427(85.6)$ & $3,511(91.3)$ & $1,196(87.9)$ & $<0.001$ \\
\hline Relatives and friends & $317(3.9)$ & $76(2.7)$ & $155(4.0)$ & $86(6.3)$ & $<0.001$ \\
\hline Colleagues & $415(5.2)$ & $96(3.4)$ & $243(6.3)$ & $76(5.6)$ & $<0.001$ \\
\hline Medical literature & $4,786(59.5)$ & $1,844(65.0)$ & $2,282(59.4)$ & $660(48.5)$ & $<0.001$ \\
\hline Online media & $492(6.1)$ & $105(3.7)$ & $264(6.9)$ & $123(9.0)$ & $<0.001$ \\
\hline
\end{tabular}


TABLE 3. Multiple logistic regression model for healthcare worker intention to accept COVID-19 vaccination, Beijing Municipality, China."

\begin{tabular}{|c|c|c|c|c|c|}
\hline \multirow[b]{2}{*}{ Variable } & \multirow[b]{2}{*}{ Value } & \multicolumn{2}{|c|}{ Univariate logistic regression model } & \multicolumn{2}{|c|}{ Multiple logistic regression model } \\
\hline & & Odds ratio $(95 \% \mathrm{Cl})$ & $P$ value & $\begin{array}{c}\text { Adjusted odds ratio } \\
(95 \% \mathrm{Cl})\end{array}$ & $P$ value \\
\hline \multirow[t]{2}{*}{ Gender } & Female & Reference & & & \\
\hline & Male & $1.07(0.95-1.20)$ & 0.279 & & \\
\hline \multirow[t]{2}{*}{ Age group } & $<40$ years old & Reference & & Reference & \\
\hline & $\geq 40$ years old & $0.82(0.74-0.91)$ & $<0.001$ & $0.90(0.77-1.06)$ & 0.197 \\
\hline \multirow[t]{3}{*}{$\begin{array}{l}\text { Occupational cohort (three } \\
\text { largest categories) }\end{array}$} & Doctors & $0.88(0.80-0.97)$ & 0.007 & $1.06(0.86-1.30)$ & 0.617 \\
\hline & Nurses & $1.14(1.04-1.25$ & 0.007 & $1.01(0.84-1.22)$ & 0.883 \\
\hline & Technicians and others & $0.99(0.87-1.12)$ & 0.87 & & \\
\hline \multirow[t]{2}{*}{ Ward type } & Other & Reference & & & \\
\hline & COVID-19 related department & $0.99(0.80-1.09)$ & 0.802 & & \\
\hline \multirow[t]{3}{*}{ Hospital level } & Level I & $0.99(0.90-1.10)$ & 0.911 & & \\
\hline & Level II & $1.21(1.04-1.35)$ & $<0.001$ & & \\
\hline & Level III & $0.85(0.78-0.94)$ & 0.001 & $1.04(0.918-1.179)$ & 0.538 \\
\hline \multirow[t]{4}{*}{ Academic degree } & Junior college and below & Reference & 0.001 & Reference & \\
\hline & Undergraduate & $1.82(1.33-2.50)$ & $<0.001$ & $1.24(0.80-1.94)$ & 0.34 \\
\hline & Masters & $1.37(1.00-1.87)$ & 0.048 & $0.97(0.64-1.47)$ & 0.877 \\
\hline & Doctor or above & $1.19(0.86-1.66)$ & 0.296 & $0.95(0.62-1.45)$ & 0.801 \\
\hline \multirow[t]{4}{*}{ Salary } & Less than 5,000 CNY & Reference & & Reference & \\
\hline & $5,000-9,999 \mathrm{CNY}$ & $1.74(1.06-2.85)$ & 0.029 & $1.06(0.54-2.06)$ & 0.874 \\
\hline & $10,000-19,999$ CNY & $1.42(0.87-2.31)$ & 0.163 & $0.99(0.52-1.91)$ & 0.98 \\
\hline & More than $20,000 \mathrm{CNY}$ & $1.30(0.78-2.14)$ & 0.314 & $1.13(0.59-2.20)$ & 0.709 \\
\hline \multirow[t]{4}{*}{ Professional ranks and titles } & No title & Reference & & Reference & \\
\hline & Junior & $1.62(1.29-2.04)$ & $<0.001$ & $1.21(0.85-1.72)$ & 0.302 \\
\hline & Intermediate & $1.45(1.24-1.69)$ & $<0.001$ & $1.30(1.01-1.69)$ & 0.044 \\
\hline & Senior & $1.03(0.88-1.21)$ & 0.723 & $0.88(0.71-1.12)$ & 0.279 \\
\hline \multirow[t]{2}{*}{ Underlying disease } & No & Reference & $<0.001$ & Reference & \\
\hline & Yes & $0.71(0.62-0.82)$ & $<0.001$ & $0.74(0.61-0.90)$ & 0.002 \\
\hline \multirow[t]{2}{*}{$\begin{array}{l}\text { Participated in the prevention } \\
\text { and control of epidemic }\end{array}$} & No & Reference & & Reference & \\
\hline & Yes & $0.87(0.78-0.96)$ & 0.005 & $1.08(0.95-1.23)$ & 0.232 \\
\hline \multirow[t]{2}{*}{$\begin{array}{l}\text { Received other vaccines in } \\
\text { the past } 3 \text { years }\end{array}$} & No & Reference & $<0.001$ & Reference & \\
\hline & Yes & $1.69(1.53-1.87)$ & $<0.001$ & $1.28(1.05-1.56)$ & 0.015 \\
\hline \multirow[t]{2}{*}{$\begin{array}{l}\text { Received seasonal influenza } \\
\text { vaccine }\end{array}$} & No & Reference & & Reference & \\
\hline & Yes & $1.85(1.65-2.08)$ & $<0.001$ & $1.43(1.15-1.80)$ & 0.002 \\
\hline \multirow[t]{2}{*}{ Perception Q1 answer } & Not serious and little serious & Reference & $<0.001$ & Reference & \\
\hline & Serious & $1.75(1.41-2.18)$ & $<0.001$ & $1.34(1.01-1.79)$ & 0.046 \\
\hline \multirow[t]{2}{*}{ Perception Q2 answer } & Unlikely & Reference & & Reference & \\
\hline & Likely and Very likely & $1.12(1.01-1.25)$ & 0.029 & $1.14(0.99-1.31)$ & 0.074 \\
\hline \multirow[t]{2}{*}{ Perception Q3 answer } & Disagree and unsure & Reference & & Reference & \\
\hline & Agree & $1.21(1.10-1.32)$ & $<0.001$ & $1.06(0.93-1.21)$ & 0.363 \\
\hline \multirow[t]{2}{*}{ Perception Q4 answer } & Disagree and unsure & Reference & & Reference & \\
\hline & Agree & $1.16(1.02-1.32)$ & 0.029 & $1.07(0.90-1.27)$ & 0.463 \\
\hline
\end{tabular}


TABLE 3. (Continued)

\begin{tabular}{|c|c|c|c|c|c|}
\hline \multirow[b]{2}{*}{ Variable } & \multirow[b]{2}{*}{ Value } & \multicolumn{2}{|c|}{ Univariate logistic regression model } & \multicolumn{2}{|c|}{ Multiple logistic regression mode } \\
\hline & & Odds ratio $(95 \% \mathrm{Cl})$ & $P$ value & $\begin{array}{c}\text { Adjusted odds ratio } \\
(95 \% \mathrm{Cl})\end{array}$ & $P$ value \\
\hline \multirow[t]{2}{*}{ Perception Q5 answer } & Disagree and unsure & Reference & & Reference & \\
\hline & Agree & $1.13(1.01-1.26)$ & 0.034 & $1.33(1.13-1.56)$ & $<0.001$ \\
\hline \multirow[t]{2}{*}{ Perception Q6 answer } & Disagree and unsure & Reference & & Reference & \\
\hline & Agree & $1.32(1.20-1.45)$ & $<0.001$ & $1.19(1.05-1.36)$ & 0.008 \\
\hline \multirow[t]{2}{*}{ Perception Q7 answer } & Disagree and unsure & Reference & & Reference & \\
\hline & Agree & $4.40(3.98-4.87)$ & $<0.001$ & $1.74(1.52-2.01)$ & $<0.001$ \\
\hline \multirow[t]{2}{*}{ Perception Q8 answer } & Disagree and unsure & Reference & & Reference & \\
\hline & Agree & $5.60(5.06-6.19)$ & $<0.001$ & $1.91(1.61-2.27)$ & $<0.001$ \\
\hline \multirow[t]{2}{*}{ Perception Q9 answer } & Disagree and unsure & Reference & & Reference & \\
\hline & Agree & $5.29(4.78-5.85)$ & $<0.001$ & $1.38(1.16-1.65)$ & $<0.001$ \\
\hline \multirow[t]{2}{*}{ Perception Q10 answer } & Not serious and little serious & Reference & & Reference & \\
\hline & Serious & $1.11(1.00-1.23)$ & 0.049 & $1.04(0.91-1.19)$ & 0.583 \\
\hline \multirow[t]{2}{*}{ Perception Q11 answer } & Not serious and little serious & Reference & & & \\
\hline & Serious & $1.07(0.98-1.18)$ & 0.137 & & \\
\hline \multirow[t]{2}{*}{ Attitudes Q1 answer } & Disbelieve and unsure & Reference & & Reference & \\
\hline & Believe & $2.90(2.59-3.24)$ & $<0.001$ & $1.23(1.04-1.44)$ & 0.015 \\
\hline \multirow[t]{2}{*}{ Attitude Q2 answer } & Disbelieve and unsure & Reference & & Reference & \\
\hline & Believe & $6.33(5.13-7.80)$ & $<0.001$ & $1.24(0.94-1.65)$ & 0.133 \\
\hline \multirow[t]{2}{*}{ Attitudes Q3 answer } & No and either is OK & Reference & & Reference & \\
\hline & Yes & $8.12(7.23-9.13)$ & $<0.001$ & $5.78(5.05-6.60)$ & $<0.001$ \\
\hline \multirow[t]{2}{*}{ Attitudes Q4 answer } & Disbelieve and unsure & Reference & & Reference & \\
\hline & Believe & $9.59(8.46-10.88)$ & $<0.001$ & $4.45(3.81-5.20)$ & $<0.001$ \\
\hline
\end{tabular}

${ }^{*}$ : Regression analyses were performed on 8,040 individuals who answered the question about their intention to get vaccinated. For the dependent variable "accept COVID-19 vaccination," answer "Yes" is assigned as 1, answer "No" or "Unsure" is assigned as 0 . If the independent variable is an unordered categorical variable, such as "Occupational cohort" and "Hospital level," it is assigned to be a dummy variable.

a policy of free vaccination and removal of barriers to vaccination, and conveyance of accurate information through appropriate channels to further enhance awareness and improve acceptance of COVID-19 vaccination of HCWs.

By the end of 2020, COVID-19 epidemic in China had gone through several stages: prevention and control of outbreaks in Wuhan City and Hubei Province; prevention and control of overseas importation-associated cases; and control of local outbreaks in Beijing, Dalian, and Urumqi. We conducted our investigation in Beijing and found that one-third of HCWs would not get vaccinated or were unsure of whether they would get vaccinated. This finding is particularly surprising in a city facing continuous risk of COVID-19 and experiencing local outbreaks.

Two factors were strongly associated with intention to get vaccinated - a policy of free vaccination and a belief that approved vaccines have been fully evaluated.
Other positively associated factors included the epidemic situation, disease severity, self-risk of infection, and the disease being preventable by vaccine. These factors make common sense and are logical. Previous vaccination with influenza or other vaccines can be interpreted as a high degree of trust in vaccines. Concerns about the safety and effectiveness of vaccines found in this study were similar to the factors reported in pandemic influenza $A(\mathrm{H} 1 \mathrm{~N} 1)$ vaccine studies (6-8).

A factor negatively associated with willingness to get vaccinated was presence of underlying disease; the association was not strong but is noteworthy. People with an underlying disease are usually a priority group for vaccination - for example, for influenza vaccination. Some countries recommend that people with underlying diseases such as controlled hypertension and diabetes receive COVID-19 vaccination. Perhaps due to confidence in the effectiveness of non-pharmacological interventions, 
Beijing HCWs who had underlying diseases tended to be more cautious - a finding worthy of further study.

A systematic review of the willingness of HCWs to receive pandemic influenza $A(\mathrm{H} 1 \mathrm{~N} 1)$ vaccination in 2009 found that willingness ranged from $13 \%$ to $89 \%$ by country and stage of the pandemic and that ultimate vaccination rates were lower than predicted (4). The main reason for lower than predicted uptake was that perception of the seriousness of the disease less than the expected seriousness (9). Under Beijing's free and voluntary influenza $A(\mathrm{H} 1 \mathrm{~N} 1)$ vaccination strategy, coverage among HCWs was $71 \%$, which was considerably higher than coverage in the general population (12.6\%) (10).

HCWs are a high-risk population for infection and potentially can serve as transmission bridges for nosocomial infection. HCWs are also important professionals for recommending vaccines to the general population. Measures should be taken to improve vaccine acceptance. Results of Phase III clinical trials and post-licensure studies should be published in peerreviewed journals to maintain openness and transparency; evidence-based evaluations should be conducted; technical guidelines from China's National Immunization Advisory Committee and professional physician associations should be widely used to provide authoritative information. Accurate information should be transmitted to leaders of professional medical associations to mobilize providers to participate fully in the vaccination effort.

Since December 2020, China has been conducting COVID-19 vaccination in key populations that include HCWs. As of the publication of this article, the vaccination rate among HCWs in Beijing exceeded the acceptance rate predicted by this survey. In addition to the free vaccination policy, timely disclosures of clinical trials results, extensive publicity of academic research by the media, and highly credible medical authorities leading the vaccination effort played important, positive roles and provided confidence in the COVID-19 vaccines and vaccination efforts. A combination of repeated social mobilizations and multiple, readily accessible vaccination opportunities further encouraged individuals who were uncertain about vaccination to choose to be vaccinated.

The study was subject to at least two limitations. First, specialist hospitals, including traditional Chinese medical hospitals, children's hospitals, maternity hospitals, dental hospitals, and hospitals closed during the epidemic were not included in the survey. Second, for each hospital sampled, only high-risk departments/ units, including emergency departments, fever clinics, respiratory system disease departments, intensive care units, medical imaging departments, and laboratory testing departments were required to be included in the study; other departments were not required to participate, and therefore participated less fully. Thus the rates of willingness to get vaccinated that we found in our survey only represent the sampled population and do not necessarily extend to all HCWs.

Conflicts of interest: No conflicts of interest declared.

\section{doi: $10.46234 / \mathrm{ccdcw} 2021.130$ \\ \# Corresponding authors: Li Lu, lulibj@163.com; Xinghuo Pang, pxh17@sina.com.}

\begin{abstract}
${ }^{1}$ Beijing Center for Disease Prevention and Control, Beijing Research Center for Preventive Medicine, Beijing, China; ${ }^{2}$ Fengtai District Center for Disease Preventionand and Control, Beijing, China; ${ }^{3}$ Changping District Center for Disease Prevention and Control, Beijing, China; ${ }^{4}$ Chaoyang District Center for Disease Prevention and Control, Beijing, China; ${ }^{5}$ Daxing District Center for Disease Prevention and Control, Beijing, China; ${ }^{6}$ Miyun District Center for Disease Prevention and Control, Beijing, China; ${ }^{7}$ Huairou District Center for Disease Prevention and Control, Beijing, China.
\end{abstract}

Submitted: March 02, 2021; Accepted: May 06, 2021

\section{REFERENCES}

1. John Hopkins University of Medicine \& Coronavirus resource center. COVID-19 Global Cases by the Center for Systems Science and Engineering (CSSE) at Johns Hopkins University (JHU). 2020. https://coronavirus.jhu.edu/map.html. [2020-9-1].

2. Lurie N, Saville M, Hatchett R, Halton J. Developing COVID-19 vaccines at pandemic speed. N Engl J Med 2020;382(21):1969 - 73. http://dx.doi.org/10.1056/nejmp2005630.

3. Haq EU, Yu JF, Guo JC. Frontiers in the COVID-19 vaccines development. Exp Hematol Oncol 2020;9(1):24. http://dx.doi.org/ 10.1186/s40164-020-00180-4.

4. del Carmen Aguilar-Díaz F, Jiménez-Corona ME, Ponce-de-LeónRosales S. Influenza vaccine and healthcare workers. Arch Med Res 2011;42(8):652 - 7. http://dx.doi.org/10.1016/j.arcmed.2011.12.006.

5. Li ZJ, Chen QL, Feng LZ, Rodewald L, Xia YY, Yu HL, et al. Active case finding with case management: the key to tackling the COVID-19 pandemic. Lancet 2020;396(10243):63 - 70. http://dx.doi.org/10. 1016/s0140-6736(20)31278-2

6. Blasi F, Aliberti S, Mantero M, Centanni S. Compliance with anti$\mathrm{H} 1 \mathrm{~N} 1$ vaccine among healthcare workers and general population. Clin Microbiol Infect 2012;18 Suppl 5:37-41. http://dx.doi.org/10. 1111/j.1469-0691.2012.03941.x.

7. Seale H, Kaur R, Wang Q, Yang P, Zhang Y, Wang X, et al. Acceptance of a vaccine against pandemic influenza $A(H 1 N 1)$ virus amongst healthcare workers in Beijing, China. Vaccine 2011;29 (8):1605 - 10. http://dx.doi.org/10.1016/j.vaccine.2010.12.077.

8. Prematunge C, Corace K, McCarthy A, Nair RC, Pugsley R, Garber G, et al. Factors influencing pandemic influenza vaccination of healthcare workers-a systematic review. Vaccine 2012;30(32):4733- 43. http://dx.doi.org/10.1016/j.vaccine.2012.05.018.

9. Gao LX, Feng LZ, Yu HJ. Analysis on KAP level and vaccination intention of population during influenza A (H1N1) pandemic. J Environ Hyg 2011;1(3):43 - 64. http://dx.doi.org/10.13421/j. cnki.hjwsxzz.2011.03.010. (In Chinese).

10. Pang XH, Liu DL, Lu L, Wang XL, Yang Z, Zhang ZJZ, et al. Factors associated with immunization of novel influenza $A(H 1 N 1)$ vaccine in Beijing, 2009. Chin J Epidemiol 2010;31(5):588-90. http://dx. doi.org/10.3760/cma.j.issn.0254-6450.2010.05.029. (In Chinese). 